\title{
ENHANCED RECOVERY (ERAS) AFTER LIVER SURGERY:COMPARATIVE STUDY IN A BRAZILIAN TERCIARY CENTER
}

\author{
Recuperação otimizada (ERAS) após cirurgia hepática: Estudo comparativo de um centro terciário brasileiro
}

Uirá Fernandes TEIXEIRA' ${ }^{1}$ Marcos Bertozzi GOLDONI ${ }^{1}$, Fábio Luiz WAECHTER ${ }^{1}$, José Artur SAMPAIO, Florentino Fernandes MENDES'2, Paulo Roberto Ott FONTES ${ }^{1}$

\begin{abstract}
How to cite this article: Teixeira UF, Goldoni MB, Waechter FL, Sampaio JA, Mendes FF, Fontes PRO. Enhanced recovery (ERAS) after liver surgery:comparative study in a brazilian terciary center. ABCD Arq Bras Cir Dig. 2019;32(1):e1424. DOI: /10.1590/0102-672020180001e1424
\end{abstract}

From the ${ }^{1}$ Serviço de Cirurgia Hepatobiliopancreática and ${ }^{2}$ Departamento de Anestesiologia, Universidade Federal de Ciências da Saúde de Porto Alegre / Santa Casa de Misericórdia de Porto Alegre ('Hepatobiliary and Pancreatic Surgical Division and ${ }^{2}$ Department of Anesthesiology, Federal University of Health Sciences of Porto Alegre / Santa Casa de Misericórdia de Porto Alegre), Porto Alegre, RS, Brazil

HEADINGS - Hepatectomy. Length of Stay. Recovery of Function. Postoperative Care.
ABSTRACT - Background: After the publication of the first recommendations of ERAS Society regarding colonic surgery, the proposal of surgical stress reduction, maintenance of physiological functions and optimized recovery was expanded to other surgical specialties, with minimal variations. Aim: To analyze the implementation of ERAS protocols for liver surgery in a tertiary center. Methods: Fifty patients that underwent elective hepatic surgery were retrospectively evaluated, using medical records data, from June 2014 to August 2016. After September 2016, 35 patients were prospectively evaluated and managed in accordance with ERAS protocol. Results: There was no difference in age, type of hepatectomy, laparoscopic surgery and postoperative complications between the groups. In ERAS group, it was observed a reduction in preoperative fasting and in the length of hospital stay by two days $(p<0.001)$. Carbohydrate loading, $\mathrm{j}$-shaped incision, early oral feeding, postoperative prevention of nausea and vomiting and early mobilization were also significantly related to ERAS group. Oral bowel preparation, pre-anesthetic medication, sub-costal incision, prophylactic nasogastric intubation and abdominal drainage were more common in control group. Conclusion: Implementation of ERAS protocol is feasible and beneficial for health institutions and patients, without increasing morbidity and mortality.

\section{Correspondence:}

Uirá Fernandes Teixeira

E-mail: uiraft@yahoo.com.br

Financial source: none

Conflict of interest none

Received for publication: 07/08/2018

Accepted for publication: 16/10/2018

DESCRITORES - Hepatectomia. Tempo de Internação. Recuperação da função fisiológica. Cuidados pós-operatórios.
RESUMO - Racional: Após a publicação das primeiras recomendações da Sociedade ERAS sobre a cirurgia do cólon, a proposta de redução do estresse cirúrgico, manutenção das funções fisiológicas e recuperação otimizada foi ampliada para outras especialidades cirúrgicas, com pequenas variações. Objetivo: Analisar a implementação dos protocolos ERAS para cirurgia hepática em um centro terciário. Métodos: Cinquenta pacientes submetidos à cirurgia hepática eletiva foram avaliados retrospectivamente, utilizando dados de prontuários, de junho de 2014 a agosto de 2016. Após setembro de 2016, 35 pacientes foram prospectivamente avaliados e manejados de acordo com o protocolo ERAS. Resultados: Não houve diferença de idade, tipos de hepatectomia, cirurgia laparoscópica e complicações pós-operatórias entre os grupos. No grupo ERAS, observou-se redução no jejum pré-operatório e no tempo de internação hospitalar de dois dias $(p<0,001)$. A carga de carboidratos, a incisão em forma de J, a alimentação oral precoce, a prevenção pós-operatória de náuseas e vômitos e a mobilização precoce também foram significativamente relacionadas ao grupo ERAS. Preparo mecânico do cólon, medicação pré-anestésica, incisão subcostal, intubação nasogástrica profilática e drenagem abdominal foram mais comuns no grupo controle. Conclusão: A implementação do protocolo ERAS é viável e benéfica para instituições de saúde e pacientes, sem aumentar a morbidade e a mortalidade. ince the publication of the first enhanced recovery after surgery (ERAS) guidelines regarding colonic resections by Gustafsson et al. in $2012^{16}$, the proposal of reduction of surgical stress, maintenance of physiological functions
optimized recovery quickly gained the attention of the international medical community. On August 2016, ERAS Society published the official recommendations ${ }^{26}$ for perioperative care for liver surgery, bringing together some experts from highvolume centers all over the world.

Since then, many papers have shown the feasibility and cost-effectiveness of implementation of enhanced recovery pathways in patients undergoing hepatectomies ${ }^{20,34}$. In several studies, this multimodal approach was consistently associated with better outcomes, including reduction in the length of hospital stay, postoperative complications and costs ${ }^{23,37}$.

Hepatic surgery represents one of the surgical specialties that most benefits from multidisciplinarity ${ }^{1,32}$, but published protocols vary widely between institutions ${ }^{33}$. Despite evidenced-based recommendations available in literature, its application did not follow this progress, mainly due to difficulties in changing paradigms ${ }^{6}$.

Liver surgery still represents a challenging operation. Despite significant 
improvements in perioperative management and surgical technique, which led to a reduction in postoperative mortality to less than $5 \%$, major hepatectomies still have a morbidity rate up to $30 \%$ in some reports ${ }^{9-11}$. This way, the implementation of evidenced-based recommendations in order to optimize perioperative recovery can greatly benefit patients and health providers ${ }^{3}$

This is a comparative study that aims to analyze the implementation of ERAS protocols for liver surgery in a tertiary center in Brazil.

\section{METHODS}

Expertise with implementation of the protocol was initially acquired with colorectal surgery, and it was later expanded to hepatectomies. A database was created with the 23 items proposed by ERAS guidelines, being subsequently filled with the collected data (Table 1).

TABLE 1 - Guidelines for enhanced recovery after liver surgery

1.Preadmission counseling
2. Perioperative nutrition
3.Perioperative oral immunonutrition
4.Preoperative fasting and preoperative carbohydrate loading
5.Oral bowel preparation
6.Pre-anesthetic medication
7.Prophylaxis against thromboembolism
8.Perioperative steroids administration
9.Antimicrobial prophylaxis and skin preparation
10. Incision
11. Minimally invasive approach
12. Nasogastric intubation
13. Drainage of the peritoneal cavity
14. Preventing intraoperative hypothermia
15. Postoperative nutrition and early oral intake
16. Postoperative glycemic control
17. Prevention of delayed gastric emptying
18. Stimulation of bowel movement
19. Early mobilization
20. Analgesia
21. Postoperative nausea and vomiting prophylaxis
22. Fluid management
23. Audit

First, it was performed a retrospective evaluation of 50 patients that underwent elective hepatic resections (without biliary anastomosis) at Federal University of Health Sciences of Porto Alegre / Santa Casa Hospital of Porto Alegre, from June 2014 to August 2016, through medical records data (group 1). Patients operated on emergency situations were excluded from analysis.

Second phase took place between September 2016 and December 2017, and represents the implementation of the protocol itself. Thirty-five patients, managed by the same hepato-pancreato-biliary team, were prospectively evaluated (group 2).

Nomenclature for liver resections was derived from Brisbane terminology ${ }^{12}$. Major hepatectomies represents removal of three or more Couinaud segments ${ }^{13}$. Definitive diagnosis was obtained from analysis of the pathologic specimen. Complications were classified according to ClavienDindo Scale ${ }^{14}$. Preoperative fasting protocol represents light meals ingestion until $6 \mathrm{~h}$ before surgery, and no more than $2 \mathrm{~h}$ for liquids. Carbohydrate loading with maltodextrin was offered to patients before operation.

The type of incison, as well as the use of prophylactic abdominal drainage, was performed according to surgeon's discretion. Normothermia during surgery was maintained using circulating water garments and intravenous warmed solutions. Patients that were at mechanical ventilation after the end of the operation received a nasojejunal tube to guarantee enteral feeding on the first postoperative day (POD1). For the remaining, a liquid oral diet was offered on POD1.

Postoperative glycemic control was performed with manual injection of insulin according to a pre-established scale. For postoperative analgesia, thoracic epidural, local anesthesia with ropivacain plus intravenous analgesia or intravenous analgesia alone were used. Postoperative nausea and vomiting prophylaxis was accomplished with at least two of the following drugs: ondansentron, metoclopramide or bromopride. All patients that underwent major hepatectomies received a central line at the beginning of the operation, for central venous pressure mensuration during liver transection. The goal was to maintain central venous pressure below $5 \mathrm{mmHg}$. When necessary, intermittent hepatic pedicle clamping was held (clamping for $15 \mathrm{~min}$, followed by $5 \mathrm{~min}$ of declamping).

\section{Statistical analysis}

Groups were tested for normality by Shapiro-Wilk test. Normal distributions were compared using Student's t test, and non-normal by Mann-Whitney test. Statistical analysis was performed in the SPSS program version 22.0.0 using the chi-square test of homogeneity, with a level of significance of $5 \%$.

\section{RESULTS}

Table 2 summarizes the participating groups. In total, 85 patients were included in the study, 50 that received the standard care and 35 patients the ERAS program. There were no differences between them regarding age, gender or type of major hepatectomy. There were also no significant differences between the groups in overall and major complications, neither in mortality rate nor pathological findings (Table 2).

The overall compliance rate before and after the implementation of ERAS protocol was $20 \%$ and $65 \%$, respectively. The median postoperative hospital stay was 5 days (2-15) in ERAS group, and $7(3-22)$ in control group $(p<0.001)$. A significant number of patients completed the preoperative fasting protocol in ERAS group (70\%), and carbohydrate loading with maltodextrin in $80 \%$ of them $(p<0.001)$. Oral bowel preparation was omitted in all patients in group 1 , and was performed in $24 \%$ of patients in group $2(p=0.001)$. Similar outcomes were obtained regarding pre-anesthetic medication $(p=0.001)$. Prophylactic nasogastric intubation was held in $62 \%$ in group 2 , and in only $11.4 \%$ in group 1 $(p<0.001)$. Following the same trend, prophylactic abdominal drainage was less common in ERAS group comparing with control (68.6\% and $92 \%, p=0.012)$.

Regarding the type of incision, the j-shaped one was more prevalent in ERAS group, and bilateral sub-costal in control $(29.4 \%$ and $69.4 \%$ respectively, $\mathrm{P}<0.001)$. Thirty-two (91.4\%) of patients started enteral feeding on POD1 in ERAS group, being $82 \%$ by oral route. This proportion was significant higher than in group $2(50 \%, p<0.001)$. Similarly, $82.9 \%$ and $88.6 \%$ of patients started postoperative early mobilization and proper postoperative nausea and vomiting prophylaxis in ERAS group ( $p=0.001)$. Of note, $100 \%$ of patients in ERAS group underwent systematic audit; this data was missing in control group. Table 3 summarizes the main outcomes. 
TABLE 2 - Characteristics of the groups.

\begin{tabular}{|l|c|c|c|} 
& ERAS & CONTROL & $p$ \\
\hline Age (years/max-min) & $58(24-78)$ & $60(22-82)$ & 0.280 \\
\hline Gender (male/female) & $16 / 19$ & $22 / 28$ & 0.350 \\
\hline Cirrhosis & $5(14.3)$ & $9(18)$ & 0.080 \\
\hline Major hepatectomy & $9(25.7)$ & $14(28)$ & 0.430 \\
\hline Hepatectomy technique & & & \\
\hline Right Hepatectomy & $3(8.6)$ & $6(12)$ & 0.093 \\
\hline Left Hepatectomy & $5(14.3)$ & $7(14)$ & 0.530 \\
\hline Trisectorectomy & $1(2.9)$ & $1(2)$ & 0.560 \\
\hline Bisegmentectomy & $15(42.9)$ & $21(42)$ & 0.570 \\
\hline Trisegmentectomy & $2(5.7)$ & 0 & 0.130 \\
\hline Atipical Resections & $9(25.7)$ & $15(30)$ & 0.059 \\
\hline Liver pathology & & & \\
\hline Colorectal Liver Metastases & $13(37.1)$ & $18(36)$ & 0.610 \\
\hline Liver Adenoma & $5(14.3)$ & $7(14)$ & 0.540 \\
\hline Hepatocellular Carcinoma & $8(22.9)$ & $12(24)$ & 0.645 \\
\hline Gallbladder Neoplasm & $1(2.9)$ & $3(6)$ & 0.124 \\
\hline Intrahepatic & $2(5.7)$ & $2(4)$ & 0.510 \\
Cholangiocarcinoma & $6(17.1)$ & $8(16)$ & 0.420 \\
\hline Other & & & \\
\hline & &
\end{tabular}

TABLE 3 - Main outcomes after ERAS implementation.

\begin{tabular}{|c|c|c|c|}
\hline VARIABLES & $\begin{array}{l}\text { ERAS } \\
(n=35)\end{array}$ & $\begin{array}{c}\text { CONTROL } \\
(n=50)\end{array}$ & $\mathrm{p}$ \\
\hline $\begin{array}{l}\text { Length of hospital stay, } \\
\text { median } \\
\text { (min-max) }\end{array}$ & $5(2-15)$ & $7(3-22)$ & $<0,001$ \\
\hline Immunonutrition & $0(0,0)$ & $1(2,0)$ & 0,928 \\
\hline Carbohydrate loading & $28(80)$ & $0(0,0)$ & $<0,001$ \\
\hline Oral bowel preparation & $0(0,0)$ & $12(24,0)$ & 0,001 \\
\hline Pre-anesthetic medication & $0(0,0)$ & $12(24,0)$ & 0,001 \\
\hline Anti-thrombotic prophylaxis & $34(97,1)$ & $48(96,0)$ & $>0,999$ \\
\hline $\begin{array}{l}\text { Perioperative steroid } \\
\text { administration }\end{array}$ & $19(543)$ & $8(40,0)$ & 0,460 \\
\hline Antimicrobial prophylaxis & $35(100,0)$ & $48(96,0)$ & 0,510 \\
\hline Incision & & & 0,001 \\
\hline J-shaped & $10(29,4)$ & $3(6,1)$ & \\
\hline Bilateral subcostal & $10(29,4)$ & $34(69,4)$ & \\
\hline Laparoscopy & $14(40,0)$ & $12(24,0)$ & 0,181 \\
\hline Nasogastric intubation & $4(11,4)$ & $31(62,0)$ & $<0,001$ \\
\hline $\begin{array}{c}\text { Prophylactic abdominal } \\
\text { drainage }\end{array}$ & $24(68,6)$ & $46(92,0)$ & 0,012 \\
\hline $\begin{array}{c}\text { Preventing intraoperative } \\
\text { hypothermia }\end{array}$ & $33(94,3)$ & $36(94,7)$ & 0,999 \\
\hline Postoperative nutrition POD1 & $32(91,4)$ & $25(50,0)$ & $<0,001$ \\
\hline Postoperative glycemic control & $24(68,6)$ & $29(58,0)$ & 0,446 \\
\hline Omental flap & $2(5,7)$ & $0(0,0)$ & 0,167 \\
\hline $\begin{array}{c}\text { Stimulation of bowel } \\
\text { movement }\end{array}$ & $6(17,1)$ & $6(12,0)$ & 0,540 \\
\hline Early mobilization & $29(82,9)$ & $19(38,0)$ & $<0,0$ \\
\hline \multicolumn{4}{|l|}{ Analgesia } \\
\hline Intravenous & $17(48,6)$ & $19(38,0)$ & 0,455 \\
\hline Epidural & $18(51,4)$ & $31(62,0)$ & 0,455 \\
\hline Local & $14(40,0)$ & $11(22,0)$ & 0,121 \\
\hline $\begin{array}{l}\text { Postoperative nausea and } \\
\text { vomiting prophylaxis }\end{array}$ & $31(886$ & $27(54,0)$ & 0,001 \\
\hline Fluid management & $27(77,1)$ & $17(81,0)$ & $>0,999$ \\
\hline Audit & $35(100,0)$ & - & - \\
\hline Overall Complications & $8(22.9)$ & $12(24)$ & 0.878 \\
\hline Dindo-Clavien $\geq 3$ & $4(11.4)$ & $7(14)$ & 0.230 \\
\hline Mortality & 0 & $1(2)$ & 0.720 \\
\hline
\end{tabular}

DISCUSSION

Enhanced recovery programs (ERP), together with the development of minimally invasive approach and strategies to improve liver hypertrophy represent the greatest advances in hepatic surgery in the last decade ${ }^{10,26,35}$. ERAS protocols are the most recent of them, bringing the concept of a multimodal pathway to achieve better results ${ }^{26}$.

Probably, the most reproduced outcome in papers comparing ERAS guidelines with traditional care is the length of hospital stay (LOS). Liang et al. ${ }^{24}$, evaluating patients that underwent laparoscopic hepatectomies according to ERAS protocols in China, showed a decrease in the median postoperative hospital stay in ERAS group of approximately three days. Similar conclusion was reported in a meta-analysis published by Li et al. ${ }^{23}$ in 2017, analyzing 254 patients treated according to ERAS guidelines. They verified that the postoperative recovery time and length of hospital stay were significantly better in this group. These two studies show that the benefit is not only related to laparoscopy itself, but also to the compilation of evidenced-based steps that work together to optimize perioperative recovery. In our work, we reduced the LOS in two days, even with the same rate of laparoscopic hepatectomies in both groups. This result is in line with recent reports ${ }^{10}$.

In our study, a significant number of patients completed the fasting protocol, with light meals intake until $6 \mathrm{~h}$ before surgery, and carbohydrate loading with maltodextrin $2 \mathrm{~h}$ before operation. These measures not only give comfort and reduce anxiety in preoperative hours, but are also related to a reduction in catabolism and insulin resistance in some papers ${ }^{2,3,14}$. Of note, we did not verified and increase in perioperative complications (like aspiration during anesthesia or postoperative pneumonia) following these recommendations. The same line of reasoning can be made for oral bowel preparation ${ }^{17}$, pre-anesthetic medication ${ }^{25}$ and prophylactic nasogastric intubation ${ }^{18,27,29}$ : its omission could be done safely.

Prophylactic abdominal drainage remains an area of uncertainty after liver surgery. Since the first evidenced-based publications regarding the use of prophylactic drains after abdominal operations $\mathrm{s}^{5,30}$, the debate about its real benefit in preventing postoperative complications after hepatic resections came to light.

A recent study by Brauer et al. ${ }^{7}$, analyzing databases of several American institutions, showed that drainage of the surgical site after hepatectomies did not improve the rate of diagnosis of major biliary leaks, in addition to increase the number of interventions, the LOS and 30-day readmissions. On the other hand, Kyoden et al. ${ }^{30}$, in 2010, questioned the design of previous studies that disfavored the routine use of drains, as well as its management in the postoperative period. Evaluating the value of prophylactic drainage in 1269 consecutive hepatectomies performed at the University of Tokyo, they concluded that prophylactic drainage was effective in reducing the frequency of subphrenic collections and biliary fistulas in a large number of patients.

Enhanced recovery pathways, in general, discourage the routine use of drains, as there is some evidence that a no-drain policy is safe and feasible after uncomplicated hepatectomies ${ }^{39}$. In our cohort, there was a significance reduction in the placement of abdominal drains in ERAS group, without increasing complications like infected collections, hemorrhage, percutaneous drainage or reoperations.

Minimally invasive liver surgery (MILS) still represents a challenge operation even for experienced surgeons ${ }^{28}$. However, after the publication of two consensus giving recommendations about laparoscopic liver resections, its use has grown and spread throughout the world, mainly because of the benefits related to the method, as less wound complications and postoperative pain, early mobilization and a decrease in $\mathrm{LOS}^{8,36}$. Despite this, it requires specific material for its adequate fulfillment, which is not available in the Brazilian public health system. Thus, in our series, even with and increase in MILS in ERAS group, the 40\% report rate is far behind from our expectations, especially when we have $68 \%$ of patients that underwent bisegmentectomies or atypical resections.

Therefore, many hepatic resections in our series were 
performed by laparotomy. Although there is not a strong recommendation regarding the better type of incision, in the intervention group a greater number of patients were operated on by a J-shaped incision, differently from control group in which a bilateral sub-costal was more prevalent $(p=0.001)$. Saving the left rectus muscle by a J-shaped incision contributes to a decrease in postoperative pain and better ventilation, with the same exposure of the operative field ${ }^{9}$.

Early enteral intake on POD1 could be resumed in the vast majority of our patients (91\%), being oral route in $82 \%$ of them. Lee et al. ${ }^{22}$, in Korea, showed that for patients undergoing liver resection, the early enteral diet (on the first postoperative day) resulted in a decrease in the LOS and faster return of gastrointestinal tract function. Yan et al. ${ }^{40}$, in a meta-analysis, reported similar benefits with early enteral feeding in surgical patients with gastrointestinal neoplasms. The enteral diet, compared to parenteral, reduced pulmonary and operative wound infections, and also the occurrence of anastomotic fistulas. We believe that the enteral diet should always be attempted; besides of previous benefits, it comforts patients without increasing morbidity, as the majority of them will be able to tolerate diet earlier in the postoperative period.

Early mobilization and adequate postoperative nausea and vomiting prophylaxis were the other steps from ERAS guidelines that could be accomplished in more than $80 \%$ of patients in the intervention group. The former requires and intensive participation of physiotherapist and nursing personnel. Yip et al. ${ }^{36}$ demonstrated that sitting out of the bed in the $1^{\text {st }} \mathrm{PO}$ and walking in the $3^{\text {rd }} \mathrm{PO}$ were factors related to compliance of ERAS protocol in their institution, which includes allowing them to be discharged within six days. We share the same opinion, and using a multidisciplinary approach we look for guaranteeing general well-being and activities of daily life as soon as possible. Regarding PONV prophylaxis, using at least two medications with different mechanisms of action represents the most recommended model for prophylaxis, and has been proposed for high-risk patients ${ }^{15}$. This strategy enables adequate enteral feeding and, ultimately, early discharge.

Interestingly, a $100 \%$ of patients underwent systematic audit in our work group, which increases the power of this study. A systematic review by Cochrane has shown that audit and feedback may represent useful strategies for improving compliance with established measures ${ }^{19}$. In addition, they reflect the results of an Institution more accurately, serving as a method to compare professionals with their peers, always seeking to achieve better outcomes.

To our knowledge, this study represents the first Brazilian experience with ERAS regarding hepatic resections, but it has some limitations. The retrospective analysis in the control group confers risks for the occurrence of selection biases and loss of data. This fact was minimized by recovering the last 50 patients operated on by our team for comparison with ERAS group, in the same way as guided by the ERAS Society. In addition, we had a small number of patients for analysis in the intervention group, which, theoretically, could limit its reproducibility in other settings. However, even with a small sample, statistical analysis showed significance at several points of the protocol, making it possible to accomplish the initial objective of the study.

\section{CONCLUSION}

Implementation of enhanced recovery protocols in liver surgery is feasible and beneficial for patients and care providers and reduced the length of hospital stay in two days. This represents a positive impact on perioperative care of patients undergoing hepatectomies, possibly saving costs without increasing morbidity and mortality. Looking for a better compliance to the established recommendations of ERAS Society may result in even better outcomes.
ACKNOWLEDGMENT

To the ERAS team of Federal University of Health Sciences of Porto Alegre (UFCSPA) / Santa Casa de Misericórdia de Porto Alegre (ISCMPA), RS, Brazil.

\section{REFERENCES}

1. Amico EC, Alves JR, João $S A$, Guimarães $P L$, Medeiros JA, Barreto ÉJ. Immediate complications after 88 hepatectomies - brazilian consecutive series. Arq Bras Cir Dig. 2016;29(3):180-184.

2. Aguilar-NascimentoJE, Bicudo-SalomaoA,CaporossiC, SilvaRM, Cardoso EA, Santos TP. Enhancing surgical recovery in Central-West Brazil: The ACERTO protocol results. e-SPEN, Eur J Clin Nutr. 2008; 3(2):e78-e83.

3. Aguilar-Nascimento JE, Bicudo SA, Waitzberg DL, Nascimento DB, Correa MI, Campos ACL, et al . ACERTO guidelines of perioperative nutritional interventions in elective general surgery. Rev. Col. Bras. Cir. 2017; 44(6): 633-648.

4. Belgihiti J, Clavien PA, Gadzijev. The Brisbane 2000 terminology of liver anatomy and resections. HPB 2000;2:333-9.

5. BelghitiJ,KabbejM,SauvanetA, Vilgrain V, PanisY,FeketeF.Drainageafter electivehepaticresection.Arandomized trial.AnnSurg.1993;218(6):748-53.

6. Bond-Smith G, Belgaumkar AP, Davidson BR, Gurusamy KS. Enhanced recovery protocols for major upper gastrointestinal, liver and pancreatic surgery. Cochrane Database Syst Rev. 2016;2:CD011382.

7. Brauer DG, Nywening TM, Jaques DP. Operative Site Drainage after Hepatectomy:A Propensity Score Matched Analysis Using the American College of Surgeons NSQIP Targeted Hepatectomy Database. J Am Coll Surg. 2016;223(6):774-783

8. Buell JF, Cherqui D, Geller DA, O'Rourke N, lannitti D, Dagher I, et al. The international position on laparoscopic liver surgery: The Louisville Statement, 2008. Ann Surg. 2009;250:825-830.

9. Chang SB, PalavecinoM,WrayCJ,KishiY,Pisters PW, VautheyJN.Modified Makuuchi incision for foregut procedures. Arch Surg. 2010;145(3):281-4.

10. Damania R, Cocieru A. Impact of enhanced recovery after surgery protocolson postoperativemorbidityand mortalityin patientsundergoing routine hepatectomy: review of the current evidence. Ann Transl Med. 2017;5(17):341.

11. D'Angelica M, Maddineni S, Fong Y, Martin RCG, Cohen MS, Ben-Porat $L$, et al. Optimal abdominal incision for partial hepatectomy: increased late complications with Mercedes-type incisions compared to extended right subcostal incisions. World J Surg. 2006;30(3):410-8.

12. DindoD, DeMartines N, ClavienPA.Classification of surgical complications: a new proposal with evaluation in a cohort of 6336 patients and results of a survey. Ann Surg. 2004;240:205-213.

13. Fortner JG, Blumgart LH. A historic perspective of liver surgery for tumors at the end of the millennium. J Am Coll Surg 2001; 193:210-222.

14. Francisco SC, Batista ST, Pena GG. Fasting in elective surgical patients: comparison among the time prescribed, performed and recommended on perioperative care protocols. Arq Bras Cir Dig 2015;28(4):250-254.

15. Gan TJ, Diemunsch P, Habib AS, Kovac A, Kranke P, Meyer TA, et al. Consensus guidelines for the management of postoperative nausea and vomiting. Anesth Analg. 2014;118(1):85-113.

16. Gustafsson UO, Scott MJ, Schwenk W, Demartines N, Roulin D, Francis $\mathrm{N}$, et al. Enhanced Recovery After Surgery Society. Guidelines for perioperative care in elective colonic surgery: Enhanced Recovery After Surgery(ERAS.) Society recommendations. Clin Nutr.2012;31(6):783-800.

17. Hokuto D, Nomi T, Yamato I, Yasuda S, Obara S, Nakajima Y. Impact of Mechanical Bowel Preparation on Postoperative Outcomes after Liver Resection for Patients with Hepatocellular Carcinoma: A Single-Center Retrospective Cohort Study. Dig Surg. 2016;33(1):51-7.

18. Ichida H, Imamura H, Yoshimoto J, Sugo H, Ishizaki Y, Kawasaki S. Randomized Controlled Trial for Evaluation of the Routine Use of NasogastricTubeDecompressionAfterElectiveLiverSurgery.JGastrointest Surg. 2016;20(7):1324-30.

19. Ivers N, Jamtvedt G, Flottorp S, et al. Audit and feedback: effects on professional practice and healthcare outcomes. Cochrane Database Syst Rev. 2012;(6):CD000259.

20. Kaibori M, Matsui $K$, Ishizaki $M$, lida H, Yoshii $K$, Asano $H$, et al. Effects of implementing an "enhanced recovery after surgery" program on patients undergoing resection of hepatocellular carcinoma.Surg Today. 2017:47(1):42-51.

21. Kyoden $Y$, Imamura $H$, Sano $K$, et al. Value of prophylactic abdominal drainagein 1269consecutivecases ofelectiveliverresection.JHepatobiliary Pancreat Sci. 2010;17(2):186-92.

22. Lee J, Kwon CH, Kim JM, Shin M, Joh JW. Effect of early enteral nutrition after hepatectomy in hepatocellular carcinoma patients. Korean J Hepatobiliary Pancreat Surg. 2012;16(4):129-33.

23. Li L, Chen J, Liu Z, Li Q, Shi Y. Enhanced recovery program versus traditional careafterhepatectomy:Ameta-analysis. Medicine(Baltimore). 2017;96(38):e8052 
24. Liang $X$, Ying $\mathrm{H}$, Wang $\mathrm{H}, \mathrm{Xu} \mathrm{H}, \mathrm{Yu} \mathrm{H}$, Cai L. Enhanced Recovery Program VersusTraditionalCareinLaparoscopicHepatectomy.Medicine(Baltimore). 2016;95(8):e2835.

25. Maurice-Szamburski A, Auquier P, Viarre-Oreal V. Effect of sedative premedication on patientexperienceaftergeneralanesthesia:arandomized clinical trial. JAMA. 2015;3;313(9):916-25.

26. Melloul E, Hubner M, Scott M, Snowden C, Prentis J, Dejong $\mathrm{CH}$, et al. Guidelines for Perioperative Care for Liver Surgery: Enhanced Recovery After Surgery (ERAS) Society Recommendations. World J Surg 2016; 40:2425-2440.

27. Nelson R, Edwards S, Tse B. Prophylacticnasogastric decompression after abdominal surgery. Cochrane Database Syst Rev. 2007;18;(3):CD004929.

28. Pais-Costa SR, Araújo SLM, Lima OAT, Martins SJ. Critical evaluation of long-term results of malignant hepatic tumors treated by means curative laparoscopic hepatectomy. Arq Bras Cir Dig. 2017;30(3):205-210.

29. Pessaux $P$, Regimbeau JM, Dondéro F, Plasse M, Mantz J, Belghiti J. Randomized clinical trial evaluating the need for routine nasogastric decompressionafterelectivehepaticresection.BrJSurg.2007;94(3):297-303.

30. Petrowsky H, Demartines N, Rousson V, Clavien PA. Evidence-based value of prophylactic drainage in gastrointestinal surgery: a systematic review and meta-analyses. Ann Surg. 2004;240(6):1074-84.

31. Reddy SK, Marroquin CE, Kuo PC, Pappas TN, Clary BM. Extended hepatic resection for gallbladder cancer. Am J Surg. 2007;194(3):355-61.

32. Rodrigues TFDC, Silveira B, Tavares FP, et al. Open, laparoscopic, and robotic-assisted hepatectomyinresection oflivertumors:anon-systematic review. Arq Bras Cir Dig. 2017;30(2):155-160.

33. Sánchez-Urdazpal González L, Salido Fernández S, Alday Muñoz Gómez Martín-Tesorero L, Molina Baena B. Implementation of an ERAS program in liver surgery. Nutr Hosp. 20157;31 Suppl 5:16-29.
34. Savikko J, Ilmakunnas M, Mäkisalo H, Nordin A, Isoniemi H. Enhanced recovery protocol after liver resection. Br J Surg. 2015;102(12):1526-32.

35. Schnitzbauer AA, Lang SA, Goessmann H, Nadalin S, Baumgart J, Farkas $S A$, et al. Right portal vein ligation combined with in situ splitting induces rapid left lateral liver lobe hypertrophy enabling 2-staged extended right hepatic resection in small-for-size settings. Ann Surg. 2012;255:405-414.

36. Wakabayashi G, Cherqui D, Geller DA, Buell JF, Kaneko H, Han HS, et al. Recommendations for laparoscopic liver resection: a report from the second international consensus conference held in Morioka. Ann Surg. 2015;261:619-629.

37. Wang C, Zheng G, Zhang W, Zhang F, Lv S, Wang A, et al. Enhanced Recovery after Surgery Programs for Liver Resection: a Meta-analysis. J Gastrointest Surg. 2017;21(3):472-486.

38. Wilmore D. From Cuthbertson to Fast-Track Surgery: 70 Years of Progress in Reducing Stress in Surgical Patients. Ann Surg. 2002;236(5):643-8.

39. Wong-Lun-Hing EM, van Woerden V, Lodewick TM, Bemelmans MHA Olde Damink SWM, Dejong CHC. Abandoning Prophylactic Abdominal DrainageafterHepaticSurgery: 10Years ofNo-DrainPolicyinanEnhanced Recovery after Surgery Environment. Dig Surg. 2017;34(5):411-420.

40. Yan X, Zhou FX, Lan T, Xu H, Yang XX, Chie CH, etal. Optimal postoperative nutritionsupportforpatientswithgastrointestinalmalignancy:Asystematic review and meta-analysis. Clin Nutr. 2017;36(3):710-721.

41. Yip VS, Dunne DF, Samuels S, Tan CY, Lacasia C, Tang J, et al. Adherence to early mobilisation: Key for successful enhanced recovery after liver resection. Eur J Surg Oncol. 2016;42(10):1561-7. 